Journal Club

Editor's Note: These short, critical reviews of recent papers in the Journal, written exclusively by graduate students or postdoctoral fellows, are intended to summarize the important findings of the paper and provide additional insight and commentary. For more information on the format and purpose of the Journal Club, please see http://www.jneurosci.org/misc/ifa_features.shtml.

\title{
The Ventromedial Ventral Pallidum Subregion Is Necessary for Outcome-Specific Pavlovian-Instrumental Transfer
}

\author{
David H. Root \\ Neuronal Networks Section, Integrative Neuroscience Research Branch, National Institute on Drug Abuse, Baltimore, Maryland 21224 \\ Review of Leung et al.
}

Learned environmental stimuli influence everyday reward and safety-seeking behaviors. During pathological conditions, such as drug addiction and obesity, learned cues influence maladaptive reward-seeking behaviors. One model of investigating the influence of learned cues upon reward-seeking behavior is outcome-specific Pavlovian-instrumental transfer (PIT). In this model, Pavlovian cues (e.g., lights or tones) are associated with distinct rewards, such as palatable foods or solutions. In separate training sessions, these same rewards are earned by responding on independent levers. During the outcomespecific PIT test, presentation of the Pavlovian cue predicting one reward increases response rates selectively on the lever that delivered the same reward. This type of PIT depends upon the integrity of the nucleus accumbens medial shell, but not nucleus accumbens core (Corbit et al., 2001; Shiflett and Balleine, 2010). Lesions of the core reduce responding levels in general, especially after reducing the value of one of the rewards through satiation (Corbit et al., 2001). These data from the Bal-

Received Sept. 19, 2013; revised 0ct. 20, 2013; accepted 0ct. 22, 2013.

This work was supported by the National Institute on Drug Abuse Intramural Research Program. I thank Lauren Root and David Barker for their insightful comments on a previous version of this manuscript.

Correspondence should be addressed to Dr. David H. Root, Neuronal Networks Section, Integrative Neuroscience Research Branch, National Institute on Drug Abuse, 251 Bayview Boulevard, Suite 200, Baltimore, MD 21224. E-mail: David.Root@nih.gov.

DOI:10.1523/JNEUROSCI.4021-13.2013

Copyright $\odot 2013$ the authors $\quad 0270-6474 / 13 / 3318707-03 \$ 15.00 / 0$ leine lab suggested the shell may mobilize reward-directed actions in response to Pavlovian cues, whereas the core may invigorate responding through a different mechanism.

The primary targets of nucleus accumbens shell and core neurons are the neurochemically distinct ventromedial (vm) and dorsolateral ( $\mathrm{dl}$ ) subregions of the ventral pallidum (VP), respectively (Zahm et al., 1996). Given the differential functions of the accumbens shell and core, it is likely that VPvm and VPdl subregions differentially participate in motivated behaviors as well. Consistent with this, VPdl neurons exhibit greater changes in firing rate than VPvm neurons specifically when rats approach and respond to self-administer cocaine (Root et al., 2013). In contrast, neurons exhibiting firing patterns after cocaine acquisition alone (retreat behavior) or during both drug-taking and following cocaine acquisition (response-retreat behaviors) were observed more often in the VPvm (Root et al., 2013). Therefore, the shell-VPvm pathway is a strong candidate for mediating goal-directed processing, a necessary component of outcome-specific PIT.

In a recently published paper, Leung and Balleine (2013) examined the influence of the shell-VPvm pathway during outcome-specific PIT, extending the known functions of the VP subregions. Three groups of rats were trained similarly, but were subsequently given different tests. Animals were first trained to associate a conditioned stimulus (CS1) with one reward and to associate a second CS (CS2) with a second reward. After this Pavlovian training, animals were trained in separate instrumental conditioning sessions to obtain the first reward by pressing one of two levers and to obtain the second reward by pressing the second lever. Following training, animals were returned to testing chambers but no rewards could be earned. After a period to reduce baseline response levels, PIT group animals received individual presentations of CS1 and CS2 cues and magazine entries and lever presses were recorded. For the lever press (LP) control group, the levers were presented to animals, but CS cues were not. Conversely, in the CS control group, the levers were not presented to animals, but the same order of CS1 and CS2 cues from the PIT group were presented. As expected, CS presentations in the PIT group elevated response rates on the levers associated with the same reward as the CS, compared with response rates before CS presentation and response rates after presentation of the CS associated with the different reward. Both PIT and CS control groups exhibited increased magazine entries after CS presentation compared with before CS presentation. LP control group animals exhibited high rates of responding in the absence of cues. 
The authors next used a measure of neural activity, c-fos immunoreactivity, and intra-VP muscimol injections to examine the role of VP in outcomespecific PIT. For these experiments, instead of examining the VPvm and VPdl subregions, VP was divided into anterior "rostromedial" and posterior "caudolateral" areas. Rostromedial VP exhibited greater c-fos immunoreactivity in the PIT group than in LP and CS control groups, whereas caudolateral VP did not. The number of c-fos immunoreactive neurons was positively correlated with PIT performance in rostromedial VP but not caudolateral VP. Furthermore, muscimol injection into rostromedial VP blocked PIT, but the effect of muscimol injection into caudolateral VP was not examined.

At first glance, these data might provide support for functional differences between anterior and posterior VP, which has been previously suggested (Smith and Berridge, 2005; Root et al., 2012; Kupchik and Kalivas, 2013). The rostromedial and caudolateral VP divisions used by Leung and Balleine (2013) contained both VPvm and VPdl subregions, somewhat limiting comparisons to previously demonstrated VP subregional differences. For example, the rostromedial panels in Leung and Balleine's (2013) Figure $2 \mathrm{~A}$ include the VPdl, and the caudolateral panels in their Figure $2 B$ include the VPvm (compare to Zahm et al., 1996, their Fig. 1).

Two additional methods used by Leung and Balleine (2013) suggest involvement of the VPvm subregion in outcome-specific PIT, however. In the first method, the retrograde tracer FluoroGold was injected into VP and c-fos immunoreactivity was examined in accumbens shell neurons coexpressing FluoroGold in the three behavioral groups. Significantly more c-fos immunoreactive shell neurons coexpressed FluoroGold in the PIT group compared with the LP and CS control groups. Given that the shell projects to the VPvm (Zahm et al., 1996; Tripathi et al., 2010), this analysis suggests a role for VPvm-projecting shell neurons in PIT. Because FluoroGold injections included both VPvm and VPdl subregions (Leung and Balleine, 2013, their Fig. 4), it would have been useful to know how core neurons, retrogradely labeled from VPdl, exhibited coexpression of c-fos immunoreactivity and FluoroGold. In the second method, the authors used a contralateral disconnection procedure in- volving unilateral shell muscimol injection together with contralateral VP muscimol injection during PIT. Disconnection of shell and VP blocked PIT, whereas unilateral muscimol injections had no effect, suggesting the shellVPvm pathway is critically involved in PIT. The earlier investigations by Leung and Balleine (2013) suggesting the involvement of anterior VP might indicate that a subpopulation of neurons in the shell-VPvm pathway is primarily involved in PIT. In fact, a distinct type of slow phasic firing pattern confined to the anterior portions of VP was observed in the minutes between cocaine self-infusions (Root et al., 2012), and this pattern has also been observed predominantly within medial shell (Fabbricatore et al., 2010), perhaps reflecting a potential difference between shell-anterior VPvm and shell-posterior VPvm pathways.

Knowledge that the shell-VPvm pathway participates in PIT provides unique insights into the neuronal circuits involved in goal-directed behavior. VPvm receives projections primarily from accumbens shell and projects to the ventral tegmental area and mediodorsal thalamus (Zahm et al., 1996; Tripathi et al., 2010, 2013), both of which are important for PIT (Corbit et al., 2007; Ostlund and Balleine, 2008). As mentioned by Leung and Balleine (2013), determination of the specific contributions of ventral tegmental area and mediodorsal thalamus-projecting VPvm neurons is of high interest. In the study of cocaine self-administration by Root et al. (2013), VPvm neurons were not only heterogeneous with respect to behavioral firing patterns, but also in firing direction (increases vs decreases from baseline). The heterogeneity of VPvm firing patterns suggests its involvement in a wide array of situations involving reward or safety-seeking behaviors. Given that intra-VP muscimol reduced PIT, one could speculate that VPvm neurons that exhibit increased firing rates during reward-seeking behaviors were involved in PIT; further testing will be necessary to examine this, however.

Another subregion of the VP, VPdl, also plays a significant role in motivated behaviors and participates in different neuronal circuits. VPdl receives projections from accumbens core and projects to subthalamic nucleus and substantia nigra pars reticulata (Zahm et al., 1996; Tripathi et al., 2010, 2013). Core neurons exhibit elevated firing rates during self-administration behaviors (Ghitza et al., 2004) and VPdl neurons primarily exhibit decreased firing rates during the cocaine selfadministering response (Root et al., 2013), likely resulting from GABAergic core projections to VPdl. In the same issue of The Journal of Neuroscience as the article by Leung and Balleine (2013), Stefanik et al. (2013) found that optogenetic inhibition of the core-VPdl GABAergic projection blocked reinstatement of drugseeking behavior induced by cocaine and drug-related cues. That is, the decreased firing rates of VPdl neurons during the drugseeking response (Root et al., 2013) were prevented, and this blocked reinstatement. Considering all these results, it is becoming increasingly clear that shell-VPvm and core-VPdl circuits differentially participate in motivated behaviors, providing a foundation to delineate the unique contributions of several neuronal circuits involved in reward-seeking behaviors.

\section{References}

Corbit LH, Muir JL, Balleine BW (2001) The role of the nucleus accumbens in instrumental conditioning: evidence of a functional dissociation between accumbens core and shell. J Neurosci 21:3251-3260. Medline

Corbit LH, Janak PH, Balleine BW (2007) General and outcome-specific forms of Pavlovianinstrumental transfer: the effect of shifts in motivational state and inactivation of the ventral tegmental area. Eur J Neurosci 26:31413149. CrossRef Medline

Fabbricatore AT, Ghitza UE, Prokopenko VF, West MO (2010) Electrophysiological evidence of mediolateral functional dichotomy in the rat accumbens during cocaine selfadministration: phasic firing patterns. Eur J Neurosci 31:1671-1682. CrossRef Medline

Ghitza UE, Fabbricatore AT, Prokopenko VF, West MO (2004) Differences between accumbens core and shell neurons exhibiting phasic firing patterns related to drug-seeking behavior during a discriminative stimulus task. J Neurophysiol 92:1608-1614. CrossRef Medline

Kupchik YM, Kalivas PW (2013) The rostral subcommissural ventral pallidum is a mix of ventral pallidal neurons and neurons from adjacent areas: an electrophysiological study. Brain Struct Funct 218:1487-1500. CrossRef Medline

Leung BK, Balleine BW (2013) The ventral striato-pallidal pathway mediates the effect of predictive learning on choice between goaldirected actions. J Neurosci 33:13848-13860. CrossRef Medline

Ostlund SB, Balleine BW (2008) Differential involvement of the basolateral amygdala and mediodorsal thalamus in instrumental action selection. J Neurosci 28:4398-4405. CrossRef Medline 
Root DH, Fabbricatore AT, Pawlak AP, Barker DJ, Ma S, West MO (2012) Slow phasic and tonic activity of ventral pallidal neurons during cocaine self-administration. Synapse 66: 106-127. CrossRef Medline

Root DH, Ma S, Barker DJ, Megehee L, Striano BM, Ralston CM, Fabbricatore AT, West MO (2013) Differential roles of ventral pallidum subregions during cocaine selfadministration behaviors. J Comp Neurol 521:558-588. CrossRef Medline

Shiflett MW, Balleine BW (2010) At the limbicmotor interface: disconnection of basolateral amygdala from nucleus accumbens core and shell reveals dissociable components of incentive motivation. Eur J Neurosci 32:1735-1743. CrossRef Medline

Smith KS, Berridge KC (2005) The ventral pallidum and hedonic reward: neurochemical maps of sucrose "liking" and food intake. J Neurosci 25:8637-8649. CrossRef Medline

Stefanik MT, Kupchik YM, Brown RM, Kalivas PW (2013) Optogenetic evidence that pallidal projections, not nigral projections, from the nucleus accumbens core are necessary for reinstating cocaine seeking. J Neurosci 33: 13654-13662. CrossRef Medline
Tripathi A, Prensa L, Cebrián C, Mengual E (2010) Axonal branching patterns of nucleus accumbens neurons in the rat. J Comp Neurol 518:4649-4673. CrossRef Medline

Tripathi A, Prensa L, Mengual E (2013) Axonal branching patterns of ventral pallidal neurons in the rat. Brain Struct Funct 218:1133-1157. CrossRef Medline

Zahm DS, Williams E, Wohltmann C (1996) Ventral striatopallidothalamic projection. IV. Relative involvements of neurochemically distinct subterritories in the ventral pallidum and adjacent parts of the rostroventral forebrain. J Comp Neurol 364:340-362. CrossRef Medline 